\title{
AN EMBEDDED SYSTEM FOR IDENTIFICATION AND
}

\section{CONFIRMATION OF AYURVEDIC PLANT USING KNOWN LEAF IMAGE DATABASE}

\author{
Nithu V.C. ${ }^{*}$, Liju Philip ${ }^{2}$, Deepa J. ${ }^{3}$ \\ ${ }^{1}$ PG Scholar, Department of Electronics and Communication Engineering, College of Engineering Chengannur, \\ Alappuzha, India \\ ${ }^{2}$ Assistant Professor, Department of Electronics and Communication Engineering, College of Engineering \\ Chengannur, Alappuzha, \\ ${ }^{3}$ Associate Professor, Department of Electronics and Communication Engineering, College of Engineering \\ Chengannur, Alappuzha, India \\ "nithuvc@gmail.com
}

\begin{abstract}
In Ayurveda, medicines are extracted from leaves, roots and stems of medicinal plants. Many a times, the plants are recognised by their leaves. Recognition of the medicinal plants from forests, fields, farms etc. is very tedious and time consuming. This paper presents the design and development of an embedded system to identify ayurvedic plants from their leaf images based on the geometric features. The system is developed based on how human beings recognize leaves in the real world. The database of known ayurvedic plants was created for the purpose which includes features of leaves extracted from twenty types of plants that have high medicinal value. The algorithms of image processing in OpenCV are used for feature extraction from leaf image. The system has been implemented on Raspberry Pi. Experiments conducted on a total of 200 leaves, 10 numbers of leaves collected from each of twenty different plants shows an average $96 \%$ accurate identification of plants from the features of their leaves
\end{abstract}

Keywords: Ayurvedic Plants, Segmentation, Feature Extraction, Image Acquisition, Medicinal Plants

\section{INTRODUCTION}

Ayurvedic medicine is one of the world's oldest medical systems. It originated in India more than 3000 years ago and remains as one of the country's traditional health care systems. Its concepts about health and disease promote the use of herbal compounds, special diets, and other unique health practices. The ayurvedic medicines have become significantly more popular all over the globe because of the healing property, less toxic and less side effects. It has been estimated that most of the world's population have confidence in traditional health care. Acceptance of traditional medicines, especially Ayurvedic medicines in the developed world is sharply increasing. But the knowledge of these medicinal plants is well known only by the ayurvedic practitioners and rural people. The proposed system used for identification and confirmation of ayurvedic plants using known leaf image database.

The plants could be identified manually by recognizing stems, flowers, leaves, fruits etc. Among all other organs flowers and leaves give more prominent identification features to many plants. The flowers on plants are seasonal but the leaves are non seasonal. Human beings identify shape of the flowers in three dimensions but the shape of leaves can be recognized in two dimensions [1]. This motivates the use of leaves as an important part in plant identification system. A leave could be identified by its different features like geometrical structures [2], veins [5], textures, colours etc.

Leaves of different plants have different structures. The query image of the leaf has to be processed before extracting the features. Different filters can be used for de-noising the image [8]. Segmentation of leaf image can be done using different methods [8] [9] [10]. In recent years, different approaches have been proposed for characterising leaf image. Otsu's method and intensity histogram based method are two of them [3] [5] [12] [13]. NIR spectral signature based medicinal plant identification studies and contour based shape descriptors for leaf images have also been proposed recently [6] [14]. Several studies on leaf identification using geometrical features have been developed [1] [2] [3] [15].

Correct identification of the medicinal leaves is an essential prerequisite to ensure safety and efficacy. In the present work eight global and two local geometrical features of 
leaves have been used for identification. A dataset is created which contains unique leaf features of commonly used medicinal plants. This dataset is used for identification and confirmation of ayurvedic plants. The database contains twenty types of leaves which are easily available in India.

The paper is organized as follows: Section II gives proposed methodology and implementation. Section III discusses the results. The paper is concluded in section IV.

\section{METHODOLOGY}

The leaf has many features like shape, texture, vein pattern, smell etc. Usually human beings can identify a leaf by recognizing its shape, texture and smell. Vein pattern is also a feature of the leaf. But the identification of leaf from vein pattern is not possible since they are too different for different leaves having same size from the same branch of a particular plant. The environmental conditions and availability of light and water also affect the overall structure of the leaf. Ayurvedic leaves which are commonly used are known by the people who work in ayurvedic field. In this work the identification is based on how human beings recognize leaves in the real world. The confirmation of the plants can be carried out using this system. Fig.1 shows the block diagram of the proposed system.

\section{Learning and database creation}

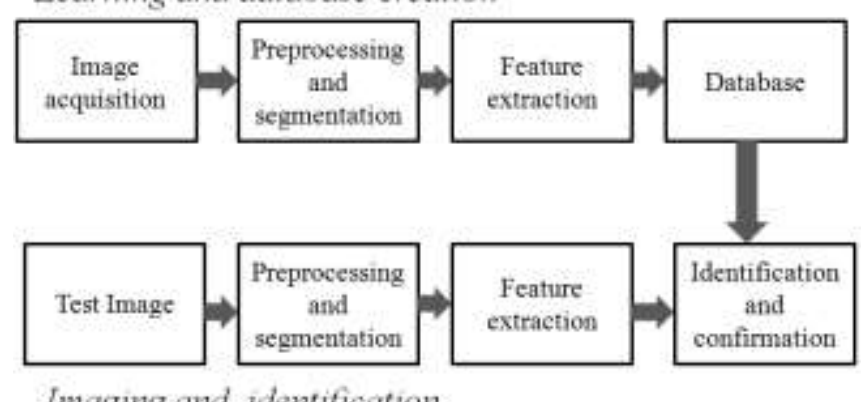

Imaging and identification

Figure 1: Block diagram of the proposed system

The leaf image is acquired using a seven megapixel digital camera. The identification is carried out by comparison of query leaf with the features of the leaves that we have in the dataset. There are two phases in this procedure, the first is learning and database creation and the next is imaging and identification. The detailed explanation is given in sections $i$ to $v$.

\section{i) Learning and database creation}

Twenty types of ayurvedic leaves were collected. While collecting the leaves, five different sized leaves from the same plants have been included. Some of the collected leaves are shown in Figure 2.

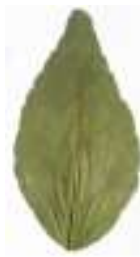

1

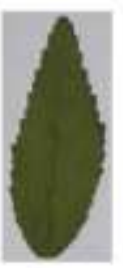

6

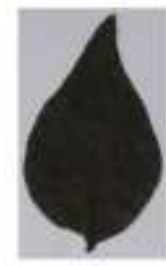

10

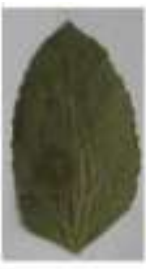

2

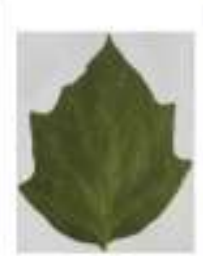

7

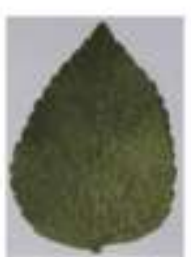

11

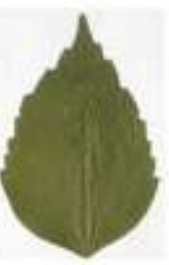

3

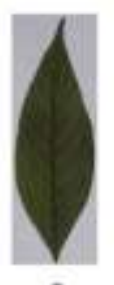

8

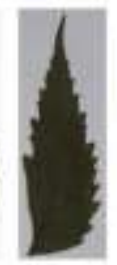

4
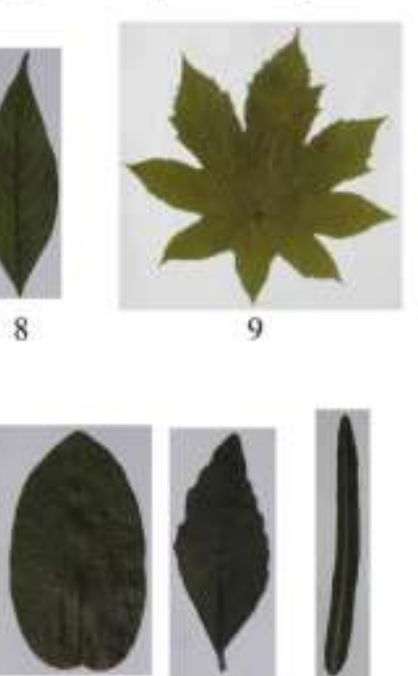

12

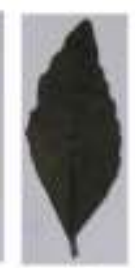

13

14
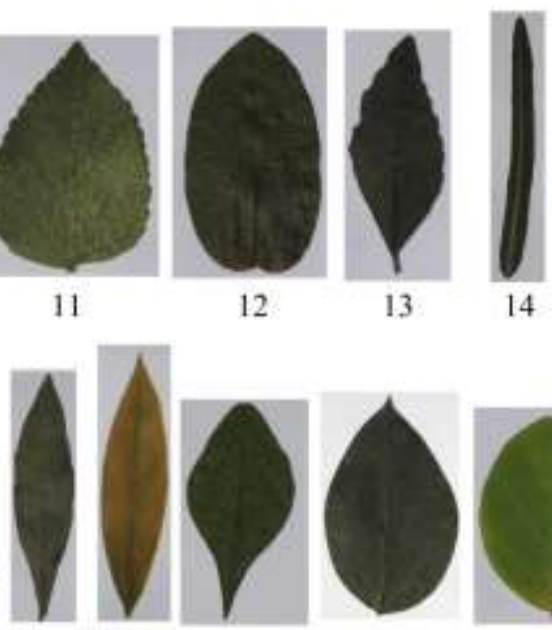

16

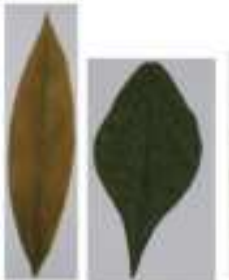

18

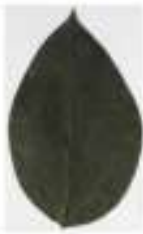

19

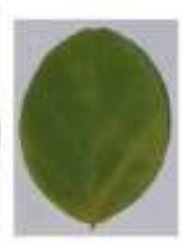

20
Figure 2: Some of the collected leaves. 1-Aegle marmrlos, 2-Thulsi, 3-Hibiscus, 4-Neem, 5-Coleus aromatic, 6-Indian ephedra, 7-Datura metel, 8-Adhatoda zeylanice, 9-Caster oil plant (Ricinus communis), 10-Commiphora caudata Wight (Hill mango), 11-Ageratum Conyzoides, 12-Ixora coccinea, 13-Curry leaf, 14-Hemidesmus indicus, 15-Centella asiatica,

16-Eclipta prostrata, 17-Turmeric(Curcuma longa), 18-

Naregamia alata, 19-Pepper, 20-Clitoria ternatea

\section{Medicinal values of collected leaves}

Aegle marmrlos: It is used for healing digestive disorders, ulcers, headache, hypertension, diabetes and numerous other ailments.

Thulsi: The extract of the leaves is a nerve tonic and it also sharpens memory. It promotes the removal of the catarrhal matter and phlegm from bronchial tube.

Hibiscus: is used for treating loss of appetite, cold, cardiac and nerve disease, upper respiratory track pain and swelling, stomach irritation and disorder of circulation; for dissolving phlegm and fluid retention

Neem: Medicines from neem clear toxins, while promoting healing and improving the whole body functions. Apart from this it destroys a wide range of parasitic organisms. It is also insecticidal and spermicidal. 
Coleus aromatic: is used for the treatment of coughs, sore throats and nasal congestion and also for a range of other problems such as infections, rheumatism and flatulence.

Indian ephedra: Roots and leaves of this plant are used for curing fever, asthma, cough and joint pain. Its leaves are used to relieve swelling and headache.

Datura metel: is used for the treatment of Rabies. The leaves of this plant help in the treatment of swelling due to the bite of vipers and poisonous insects.

Adhatoda zeylanice: It is used to treat chronic cough, asthma and bronchitis and it relieves congestion in the chest. It is used to treat local bleeding. It is also used as blood purifier.

Castor oil plant: Castor oil plant has many medicinal properties. It promotes antioxidant activity, antitumour activity, bone regeneration activity, anti-implantation activity, anti-asthmatic activity and anti-nociceptive activity. Commiphora caudata Wight: The bark and leaves are used for curing diabetes, low back pain, sciatica, fever, arthritis and urinary retention. It is also used as an anti-ulcerogenics agent.

Ageratum Conyzoides: It is anti inflammatory. It is used to treat cuts, wound, snakebites, rheumatism, cough and cold.

Ixora coccinea: Depending on the medical condition, the leaves, roots and the stem are used to treat various ailments. The plant contains important phytochemicals such as lupeol, ursolic acid. The plant possesses antioxidative, antibacterial, gastroprotective, hepatoprotective and antidiarrhoal properties.

Curry leaf: Curry leaves are natural flavouring agents with a number of health benefits. It stops diarrhea, gives gastrointestinal protection. It has antioxidant and antidiabetic properties. It also fights against cancer

Hemidesmus indicus: The root of this herb is used as a tonic, blood purifier and diuretic. It is also used in the treatment of rheumatism, diseases to urinary tract and skin infections.

Centella asiatica: It is used in the treatment of anxiety and treatment of wound, burns and ulcerous skin ailments. It is used in prevention of keloid and hypertrophic scars. It is also used for the treatment of neuro toxic snake bite.

Eclipta prostrate: This is used as a liver tonic. It is rejuvenative and is especially good for hair. It is use in preparing oil and that helps the growth of thick natural colour hair.

Turmeric: Turmeric is used in healing many health disorders like, liver problems, digestive disorders, treatment of skin diseases and healing wound. It is anti-inflammatory.

Naregamia alata: It is useful in healing wounds, ulcers, halitosis, cough, asthma, bronchitis, splenomegaly, scabies, pruritus, dysentery, dyspepsia, catarrh, anaemia and chronic and malarial fever.

Pepper: Pepper has antibacterial, anti-oxidant and antiinflammatory properties. It is used for the treatment of cough, intestinal problems, cancer etc.

Clitoria ternatea: It is used for the treatment of cold, cough, asthma, small pox, fever and piles. It is also used in the treatment of fertility and digestive problems. It is a stress reliever and an antidote to poisonous bites.
For creating database, the collected leaves are kept pressed for three weeks to get its exact shape. For each leaf, separate database has been created with unique features.

\section{ii) Leaf image acquisition}

The image is captured in natural light which is an RGB image. The image background needs to be clean and preferably uniform with reasonable contrast with the colour of the leaf. 14 Megapixels Panasonic camera (Model: DMCFH20) is used for image acquisition.

\section{iii) Image pre-processing and segmentation}

The main goal of image pre-processing and segmentation is identifying the leaf from an image and discarding all the other background details. For this image de-noising bilateral filter is applied [11]. Edge preserving character of bilateral filter helps to save the edges of the image. The bilateral filter is defined as

$I^{\text {filtered }}(x)=\frac{1}{W_{p}} \sum_{x_{i \in \Omega}} I\left(x_{i}\right) f_{r}\left(\left\|I\left(x_{i}\right)-I(x)\right\|\right) g_{s}\left(\left\|x_{i}-x\right\|\right)$

Where normalization term

$W_{p}=\sum_{x_{i} \in \Omega} f_{r}\left(\left\|I\left(x_{i}\right)-I(x)\right\|\right) g_{s}\left(\left\|x_{i}-x\right\|\right)$

where, $I^{\text {filtered }}$ is the filtered image, $I$ is the input image to be filtered, $\mathrm{x}$ is the coordinates of the current pixel to be filtered, $\Omega$ is the window centred in $\mathrm{x}, f_{r}$ is the range for smoothing differences in intensities, $g_{s}$ is the spatial kernel for smoothing difference in coordinates. $f_{s}$ and $g_{s}$ can be a Gaussian function.

The filtered image is then segmented using Otsu's threshold, which reduces gray level image to a binary image [12] [13][16]. Otsu's method finds out the threshold that minimizes the intra-class variance, as a weighted sum of variances of the two classes:

$\sigma_{w}^{2}(t)=w_{1}(t) \sigma_{1}^{2}(t)+w_{2}(t) \sigma_{2}^{2}(t)$

Weights $w_{i}$ are the probabilities of the two classes separated by a threshold $\mathrm{t}$ and $\sigma_{i}^{2}$ variances of these classes.

In binary image, the background pixels are set to ' 0 ' or black and the pixels within the leaf is set to ' 1 ' or white.
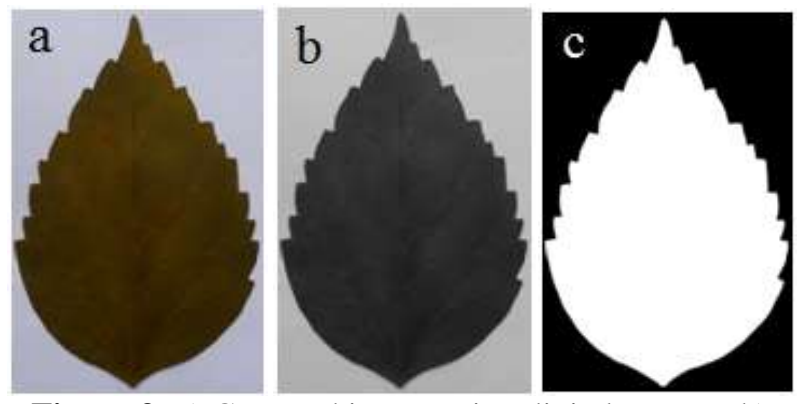

Figure 3: a) Captured image using digital camera. b) Greyscale image. c) Segmented image. 


\section{iv) Feature extraction}

Once the pre-processing is done, feature extraction is carried out. Contour is considered as one of the major geometrical features. Contours can be explained simply as a curve joining all the continuous points (along the boundary), having same colour or intensity. Contours are retrieved from the binary image by using the algorithm in OpenCV. The contours are useful for shape analysis and object detection and recognition. Figure 4 shows the extracted contour of Castor oil leaf.

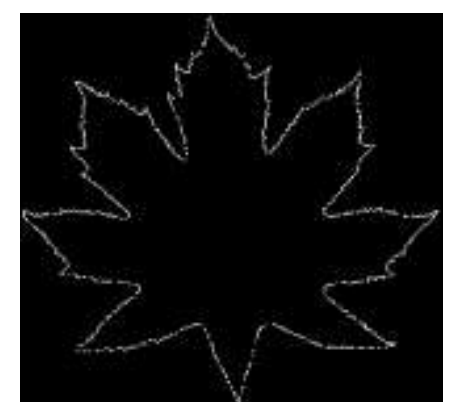

Figure 4: Contour of Castor oil leaf

Remaining features are calculated based on extracted contour.

a) Area: Area represents number of pixels in the leaf region. Binary form of our leaf image has black background and white inside leaf region, number of white pixels represents the area of the leaf.

b) Major Axis: Major axis is denoted as a line, which lies between apex and base of the leaf.

c) Minor Axis: Minor axis of the leaf that has same normalized second central moment as the leaf region.

d) Image moment: an image moment is a certain particular weighted average (moment) of the image pixels' intensities.

e) Centroid: is the centre of mass of an object of uniform density.

f) Perimeter: Perimeter is the distance along the boundary of the leaf.

g) Convex Hull: Convex hull represents the smallest convex polygon that encapsulates the leaf region.

h)

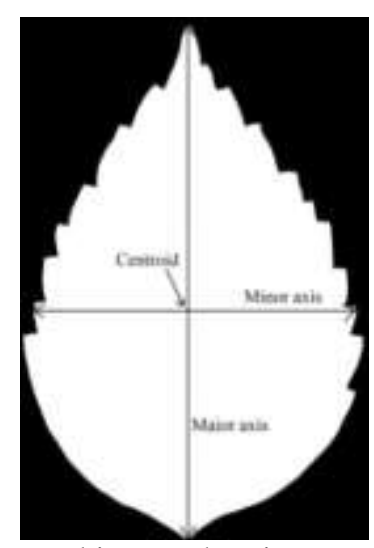

Figure 5: Segmented image showing centroid, major axis and minor axis.
From these basic measurements the following parameters are evaluated

a) Minor axis length ratio of major axis length $\left(R_{m m}\right)$ : This feature is denoted as ratio of minor axis length to major axis length.

b) Perimeter Ratio of Manor Axis Length $\left(R_{P M}\right)$ : It is denoted as the ratio of leaf perimeter to manor axis length.

c) Solidity $(S)$ : Solidity is the ratio of contour area to its convex hull area.

d) Equivalent diameter ratio of minor axis $\left(R_{E M}\right)$ : Equivalent diameter ratio of minor axis is the ratio of equivalent diameter to the minor axis length. Equivalent diameter is the diameter of the circle whose area is same as the contour area of the leaf.

e) Aspect Ratio (AR): It is the ratio of width to height of bounding rectangle of the leaf.

f) Extent $(E)$ : Extent is the ratio of contour area to its convex hull area.

g) Roundness: It is ratio of area and perimeter with some constants.

h) Rectangularity (Rect): It is calculated as ratio of area and product of major axis length and minor axis length.

The Table-I shows the features extracted from different leaves.

Apart from the global based approach two new major local based approaches are used. In the first local approach the leaf image is cropped into four regions and presence of leaf part in each region is analysed. Cropping is based on the centroid of the leaf image. The extreme points on four sides of the image are found out based on the centroid. Then the image is cropped through the lines joining these points on opposite sides.

The second approach is the analysis of margins of leaves. Some leaves have notches on its margin. The number of notches $\left(\mathrm{N}_{\mathrm{N}}\right)$ and depth of notches $\left(\mathrm{N}_{\mathrm{D}}\right)$ of each leaves are calculated. Row based differentiation of contour matrix is taken to find out the presence of notch. Only half portion of the leaf is considered for margin analysis.

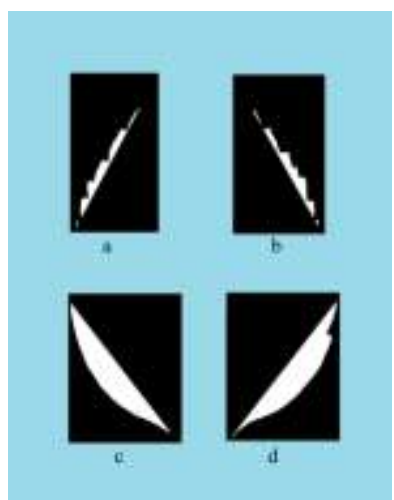

Figure 6: Separated four regions. (a) Top left region $\left(T_{L}\right)$. (b) Top right region $\left(T_{R}\right)$. (c) Bottom left region. (d) Bottom right region 
Table I: Features of leaves

\begin{tabular}{|c|c|c|c|c|c|c|c|c|c|}
\hline Sl. No. & Name of plants & AR & $\mathrm{R}_{\mathrm{PM}}$ & $\mathrm{R}_{\mathrm{MM}}$ & Roundness & $\mathrm{R}_{\mathrm{EM}}$ & $\mathrm{E}$ & $\mathrm{S}$ & Rect \\
\hline 1 & Hibiscus & $0.63-0.68$ & $4.7-5.59$ & $0.66-0.73$ & $0.58-0.71$ & $1.13-1.18$ & $0.55-0.62$ & $0.91-0.96$ & $0.71-0.75$ \\
\hline 2 & Caster oil plant & $1-1.08$ & $7.6-8.8$ & $0.9-0.92$ & $0.11-0.16$ & $0.94-0.97$ & $0.43-0.47$ & $0.6-0.64$ & $0.63-0.66$ \\
\hline 3 & Adhatoda zeylanice & $0.25-0.35$ & $7.4-9.5$ & $0.26-0.36$ & $0.40-0.5$ & $1.6-2$ & $0.6-0.63$ & $0.95-0.96$ & $0.75-0.78$ \\
\hline 4 & Datura metel & $0.57-0.81$ & $4.2-5.1$ & $0.58-0.82$ & $0.61-0.64$ & $1.05-1.3$ & $0.57-0.6$ & $0.88-0.93$ & $0.72-0.74$ \\
\hline 5 & Thulsi & $0.47-0.58$ & $4.7-5.59$ & $0.49-0.59$ & $0.58-0.71$ & $1.2-1.5$ & $0.64-0.71$ & 0.96-0.99 & $0.76-0.79$ \\
\hline 6 & Clitoria ternatea & $0.6-0.75$ & $3.5-4.5$ & $0.65-0.75$ & $0.75-0.85$ & $1.1-1.3$ & $0.78-0.84$ & $0.98-1$ & $0.783-0.786$ \\
\hline 7 & Coleus aromatic & $0.8-1$ & $3.8-4.45$ & $0.8-1$ & $0.5-0.7$ & $0.9-1.1$ & $0.66-0.7$ & $0.94-0.96$ & $0.74-0.77$ \\
\hline 8 & Neem & $0.3-0.34$ & $10.1-10.4$ & $0.26-0.3$ & $0.26-0.28$ & $1.6-1.71$ & $0.49-0.55$ & $0.82-0.85$ & $0.6-0.67$ \\
\hline 9 & Hemidesmus indicus & $0.07-0.2$ & $16-26$ & $0.05-0.14$ & $0.01-0.2$ & $1.6-3.5$ & $0.3-0.68$ & $0.5-0.92$ & $0.2-0.7$ \\
\hline 10 & Cyperus rotundus & $1-1.4$ & $4.2-5$ & $0.67-0.87$ & $0.53-0.6$ & $1-1.15$ & $0.6-0.76$ & $0.83-0.9$ & $0.68-0.74$ \\
\hline 11 & Indian ephedra & $0.35-0.4$ & $7-7.7$ & $0.33-0.39$ & $0.45-0.48$ & $1.5-1.7$ & $0.61-0.64$ & 0.94-0.96 & $0.72-0.74$ \\
\hline 12 & Eclipta prostrata & $0.15-0.26$ & $10-14.4$ & $0.15-0.26$ & $0.25-0.38$ & $1.9-2.4$ & $0.6-0.62$ & $0.93-0.96$ & $0.75-0.78$ \\
\hline 13 & Aegle marmrlos & $0.36-0.57$ & $4.7-7.4$ & $0.39-0.6$ & $0.43-0.71$ & $1.2-1.6$ & $0.53-0.65$ & 0.9-0.99 & $0.73-0.77$ \\
\hline 14 & Commiphora caudata & $0.61-0.73$ & $4-4.6$ & $0.65-0.8$ & $0.6-0.75$ & $1-1.17$ & $0.5-0.65$ & $0.92-0.97$ & $0.7-0.75$ \\
\hline 15 & Ixora coccinea & $0.43-0.55$ & $5-5.8$ & $0.43-0.56$ & $0.67-0.72$ & $1.3-1.6$ & $0.74-0.76$ & $0.99-1$ & $0.77-0.79$ \\
\hline 16 & Curry leaf & $0.35-0.41$ & $6.6-7.5$ & $0.35-0.45$ & $0.45-0.51$ & $1.5-1.6$ & $0.53-0.57$ & $0.92-0.94$ & $0.74-0.77$ \\
\hline 17 & Ageratum Conyzoides & $0.61-0.74$ & $4.1-4.7$ & $0.65-0.75$ & $0.65-0.71$ & $1.1-1.3$ & $0.67-0.69$ & 0.97-0.98 & $0.73-0.77$ \\
\hline 18 & Turmeric & $0.1-0.3$ & $8.1-12$ & $0.2-0.35$ & $0.34-0.5$ & $1.8-2.5$ & $0.64-0.71$ & 0.98-0.99 & $0.78-0.79$ \\
\hline 19 & Pepper & $0.62-0.76$ & $3.9-4.5$ & $0.63-0.76$ & $0.76-0.8$ & $1.1-1.25$ & $0.66-0.68$ & 0.97-0.99 & $0.73-0.77$ \\
\hline 20 & Naregamia alata & $0.4,0.51$ & $5.25,5.8$ & $0.4,0.52$ & $0.5,0.61$ & $1.3,1.4$ & $0.54,0.59$ & $0.88,0.95$ & $0.69,0.75$ \\
\hline
\end{tabular}

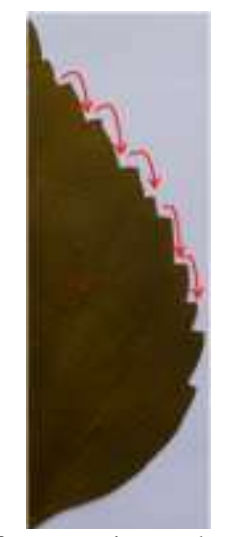

Figure 7: Half leaf for margin analysis. Red arrow shows the notches

\section{v) Implementation}

The proposed system is implemented in a single board computer. Raspberry Pi (model $\mathrm{B}+$ ) is used as the hardware platform. OpenCV and the language Python is used for writing the image analysis algorithm. The operating system used is Raspbian.

\section{RESULT ANALYSIS}

The leaves of twenty types of plants and five leaves from each plant are used for database creation. Global based approach is carried out followed by local based approach. Initially contour of the leaf is found out and from that different geometrical ratios are calculated. Local based approaches are considered for increasing the accuracy of identification and confirmation. Margin analysis increases the recognition accuracy for serrated margin leaves. All the features mentioned in Table I and local features used in the database creation are extracted from query leaf and compared with the features in the database. Percentage of similarity with each leaf in the database is calculated using these comparison results and a threshold value of similarity percentage is setup. The system is tested using ten leaves of each type and the result is shown in the figure 8 and figure 9. Name of the leaves versus number of leaves recognized is given in the graphs. System is tests using 10 Megapixels SLR camera shows an excellent improvement in percentage of accurate detection. When using digital camera with 5MP, some leaves (Aegle marmrlos, Thulsi, Hibiscus, Coleus aromatic, Caster oil plant, Ageratum conyzoides, curry leaf, Hemidesmus indicus, Turmeric) are poorly recognized. Camera with high resolving power (10 MP SLR Camera) increases the number of recognition of the above mentioned leaves. This is due to the fact that the high pixel count makes it possible to analyze the micro features at the margins of the leaves. The number of recognition of other leaves (Neem, Indian ephedra, Datura metel, Adhatoda zeylanice, commiphora caudata, Ixora coccinea, Cyperus rotundus, Eclipta prostrate, Naregamia alata, Clitoria ternatea) also increases when the camera with double the pixel count is used.

It is obvious that the most accurate result could be obtained by adopting the approach mentioned and by increasing the resolving power of the camera to be used for imaging. 


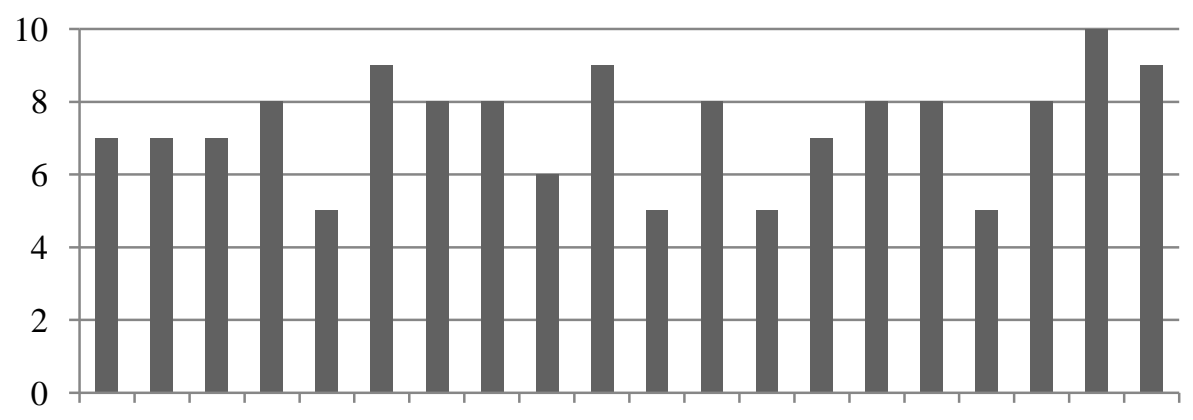

- Number of leaves recognized

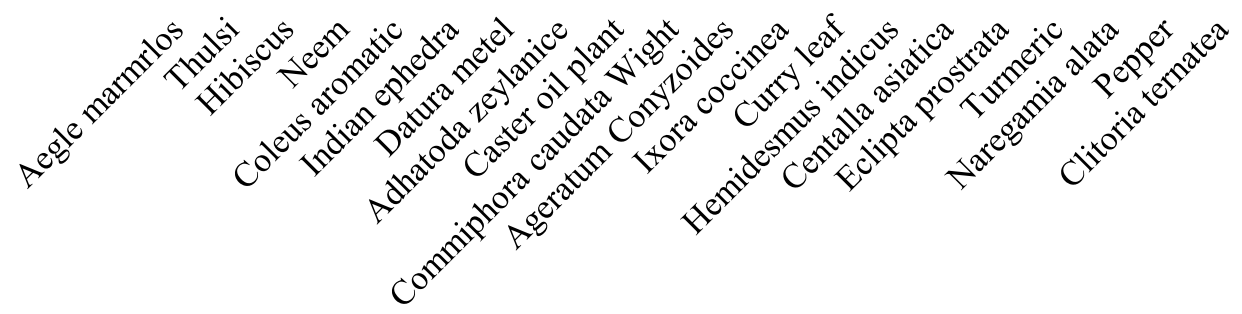

Figure 8: Result of system testing (Image captured by 5 MP camera)

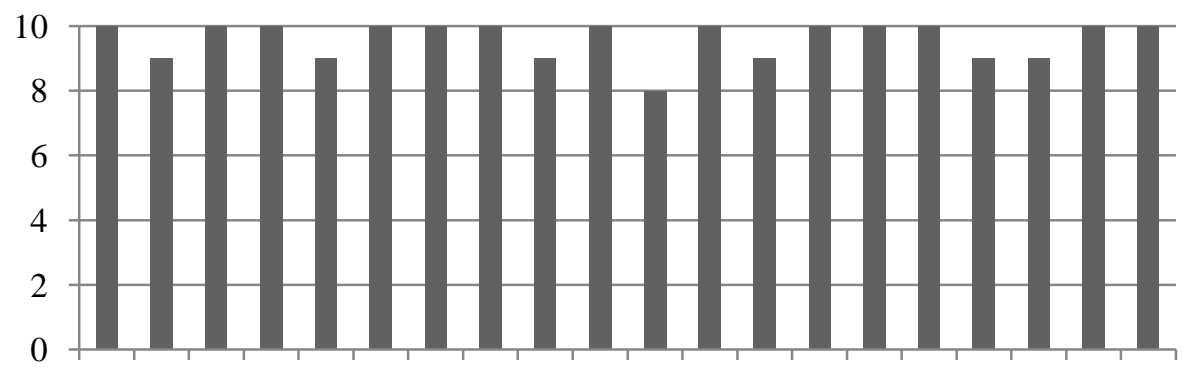

number of leaves recognized

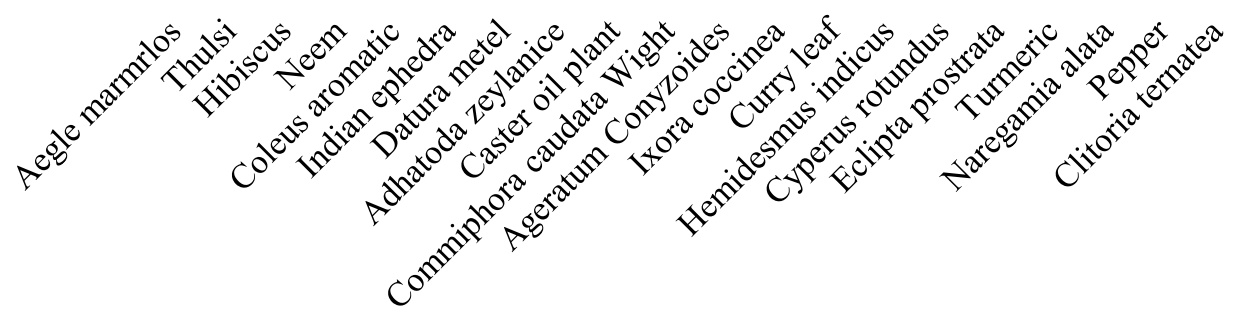

Figure 9: Result of system testing (Image captured by 10 MP digital SLR camera)

\section{CONCLUSION}

An embedded system for identification and confirmation of ayurvedic leaves has been developed based on leaf image feature database. This system adopts geometrical feature ratios, part based approaches and margin information for accurate identification and confirmation. Combined features of each leaf are suitable for accurate recognition. The experimental results show an excellent level of accuracy in identification and confirmation of Ayurvedic leaves. To use this system in the real world an SLR camera with a very high resolving power is recommended.

\section{REFERENCES}

[1] Nandyal, S.S., Anami, B.S.and Govardhan, A. (2013) 'Base and apex angles and margin types-based

Identification and classification from medicinal plants' leaves images', Int. J. Computational Vision and Robotics, Vol. 3, No. 3, pp.197-224.
[2] Uluturk, C., Ugur, A. 'Recognition of leaves based on morphological featuresderi ved from two half-regions', 'Innovation in Intelligent System and Applications(INISTA),2012 International Symposium'.

[3] Parag Bhandarkar, Harshal Doshi, Mamata Kadakia, Rizwan Ahmed. (2014) 'Leaf Identification Using Morphology and Structural Decomposition', International conference on Signal Processing and Integrated Networks(SPIN).

[4] Javed Hossain, M. Ashraful Amin. 'Leaf Shape Identification Based Plant Biometrics'. Proceedings of $13^{\text {th }}$ International Conference on computer and Information Technology (ICCIT 2010)

[5] H.Fu ,Z. Chi (2006) 'Combined thresholding and nural network approach for vien pattern extraction for leaf image', IEE Proc. -Vis. Image Signal

Process. Vol. 153, No. 6. 
[6] P. Kelina Sahaya Rajesh, C.Kumaravelu, A. Gopal (2013). 'Studies on Identification of Medicinal Plant Variety Based on NIR Spectroscopy Using Plant Leaves'.

[8] Rafael C. Gonzalez, Richard E. Woods, Digital Image Processing, Second Edition. 2002 by Prentice-Hall, Inc.Upper Saddle River, New Jersey 07458

[9] Shankar Rao, Hossein Mobahi, Allen Yang, Shankar Sastry and Yi Ma, "Natural Image Segmentation with Adaptive Texture and Boundary Encoding", Proceedings of the Asian Conference on Computer Vision (ACCV) 2009, H. Zha, R.-i. Taniguchi, and S. Maybank (Eds.), Part I, LNCS 5994, pp. 135--146, Springer

[10] Richard O. Duda, Peter E. Hart, David G. Stork, Patern Classificatoin, Second edition, by Wiley India Pvt. Ltd.,New Delhi - 110002

[11] Carlo Tomasi and Roberto Manduchi, "Bilateral filtering for gray and color images," in Computer Vision, 1998. Sixth International Conference on . IEEE, 1998, pp. 839- 846.

[12] Nobuyuki Otsu (1979). "A threshold selection method from gray-level histograms". IEEE Trans. Sys., Man., Cyber [13] Rafael C. Gonzalez, Richard E. Woods, Steven L.Eddins,Digital Image Processing Using MATLAB®, Second Edition 2009By GatesMark Publishig®.

[15] Farzin Mokhtarian and Sadegh Abbasi. 'Matching Shapes With Self-Intersections: Application to Leaf Classification'. IEEE Transaction on Image Procesing, Vol.13, No.5, May 2004.

[16] M. Sezgin and B. Sankur (2004). "Survey over image thresholding techniques and quantitative performance evaluation". Journal of Electronic Imaging 